\title{
The Impact of Change from Hierarchy to Teams in Two Academic Libraries: Intended Results versus Actual Results Using Total Quality Management
}

\author{
Irene Owens
}

The current trend in examining library administrative structures to accommodate change is common in library literature. The team approach, used within the construct of Total Quality Management, is examined in this case study, after which the case study is compared with a similar change that took place at Duke University. This article seeks to ascertain the degree to which the goals of the change are met and/or exceeded. The implications for change from hierarchal to team management hold many possibilities that extend beyond those received by traditional means, benefitting the full-time staff and customers, as well as student assistants. Student assistants make up a large portion of the part-time academic library staff and offer a sometimes "untapped" resource. The inclusion of students in comprising teams may be a refreshing and productive change in management structure. The article questions a real change from hierarchy to teams and also suggests that librarianship may need to redefine the meaning of "profit" in a nonprofit environment.

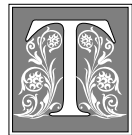

he study of modern management began in the for-profit sector and since its beginning has generally affected what has happened in the not-for-profit sector. The fact that academic courses that specifically address not-for-profits continue to be offered, particularly in schools of business, implies that significant differences still exist between the two approaches. One of the major differences listed by William $H$. Newman and
Harvey W. Wallender III is that for-profit organizations tend to know much more about their customers than do not-forprofits and, therefore, there is a weak customer influence on not-for-profits. ${ }^{1}$ Two trends that represent differences between the not-for-profit and for-profit sectors have to do with their relative emphasis on benchmarking-the search for industry's best practices that leads to superior performance, marketing, and total quality management (TQM). Gener-

Irene Owens is an Assistant Professor in the Graduate School of Library and Information Science at the University of Texas at Austin; e-mail: iowens@gslis.utexas.edu. 


\section{College \& Research Libraries}

ally, the for-profit sector places greater emphasis on the incorporation of modern practices than the not-for-profit sector does.

\section{Case Study}

The purpose of this article is to develop a case study from the author's research conducted in 1996 at a southwestern university, where a change was made from hierarchy to teams within the context of TQM. The article then compares the case study from that research with a similar change from hierarchy to teams, also within the context of TQM, at Duke University as reported in an article by John Lubans. ${ }^{2}$ Because the researcher promised anonymity to the southwestern institution and to the participants in the survey and interviews, they are referred to here as university $X$.

\section{A key problem in using teams rather than hierarchy is that organizations do not hire, fire, and promote teams but, instead, hire, fire, and promote individuals.}

The shift from hierarchy to teams in both libraries involved the adoption and incorporation of TQM principles. A quick look at the development of management theory reflects the results that were historically related to various approaches. Frederick Taylor, father of the scientific management approach, placed a great emphasis on efficiency. Henri Fayol, of the classical movement, wanted his approach to result in more clearly defined roles for managers. Fayol also identified universal principles (unity of command, division of work, authority, discipline, unity of direction, centralization, etc.) with the ultimate result of building a unified theory of management. Max Weber emphasized optimally tight and appropriate hierarchical structures. Elton Mayo, Mary Follett, and associates stressed the collective importance of groups, individuals, esprit de corps, and productivity. The contingency school of management stressed the eclectic and
November 1999

situational use of multiple managerial approaches, and W. Edwards Deming stressed a focus on processes, outcomes, and quality. This research consolidates these various managerial approaches in addressing the problem of organizational change that seeks to move from an emphasis on hierarchy to teamwork.

\section{Theory and Background}

The use of hierarchy, a means of layering the staff of an organization into categories of work responsibilities and accountability, has been in existence for at least three millennia. A major criticism of hierarchy is that, although it was appropriate for the Industrial Age, it is no longer a good structure for dealing with the increasing amount of change faced in the late twentieth century's Information Age. Another criticism of hierarchy is that it allocates too large a percentage of decision making (and therefore power) to the top of the pyramid.

One of the means by which the problems of hierarchy are being addressed is that of instituting a team approach in the management of academic and other libraries. On the other hand, Elliott Jaques noted that a change from hierarchy to some other structural form is not needed for today's Information Age but, instead, what is needed is a better understanding of how hierarchy should work. According to Jaques, the need is managerial hierarchy that understands its own nature and purpose. Hierarchy is the only structure that allows an organization to employ large numbers of workers and to preserve accountability for the work they do. ${ }^{3}$ A key problem in using teams rather than hierarchy is that organizations do not hire, fire, and promote teams but, instead, hire, fire, and promote individuals. This is not to say that hierarchy is not without problems. One of the most pronounced problems is too much layering. When too much layering is used, it can bring out the worst in human nature (greed, insensitivity, coercion, and self-importance). Additionally, Jaques stated: "The trouble is that com- 
The Impact of Change from Hierarchy to Teams 573

panies need two to three times as many pay grades as they do layers, and once they have established the pay grades, which are easy to describe and set up, they fail to take the next step and set up a different managerial hierarchy based on responsibility rather than salary." 4 The result is too many layers. Despite the drawbacks of hierarchy, however, attempting to throw out the structure is not the answer. Rather, the hierarchy can serve as a platform for the evolution of team approaches.

John R. Katzenbach and Douglas K. Smith stated that teams require both individual accountability and team accountability. Just as Jaques advised correction to the structure of hierarchy, Katzenbach and Smith suggested ways in which the team approach may be better understood and used more effectively. For teams to work successfully, values must be used to bring out the best in human nature. According to Katzenbach and Smith:

Team work represents a set of values that encourage listening and responding constructively to views expressed by others, giving others the benefit of the doubt, providing support, and recognizing the interests and achievements of others. ${ }^{5}$

In addition to using values to help teams work more successfully, there is a need to have what Katzenbach and Smith call a "collective work project," where members work together and share the common commitment to, and purpose of, a project. Katzenbach and Smith thus see performance results as the hallmark of teams.

Using the perspectives of Jaques and Katzenbach and Smith, it would appear that the proper use of hierarchy and the proper use of teams can be made to complement each other in a management structure. However, other factors must be considered. Herbert White issued a caveat by stating that teams are not always the best approach for all tasks and, more important, that teams can be structured to exclude persons that may not fulfill individual preferences and prejudices. ${ }^{6}$

In addition to deciding which is the better approach to use (hierarchy or teams) and when it is decided that a change is needed, managers must face the challenge of implementing the change. In having to decide whether a change in structure is needed, managers and employees are having, at the same time, to keep abreast of the myriad changes that occur daily in the Information Age. An additional problem is that managers and employees may view change differently. Thomas R. Harvey reported that the manner in which change is accepted by employees may depend more on how it is introduced than on any other factor. ${ }^{7}$ Harvey provides a step-by-step guide for introducing change so that, among other things, managers can defend the reasons a change is needed and the ways it will benefit both the employees and the organization.

\section{Total Quality Management}

One of the ways that libraries have introduced change has been through the implementation of TQM. TQM focuses on the examination of "processes" by which services are delivered and aims to achieve better-quality service for customers. It also attempts to flatten the organizational structure by permitting and encouraging staff to play a larger role in the decision-making process. One of the requirements of TQM is that there be flexibility and empowerment, both of which may be accomplished through teamwork. A specific team approach, the self-directed work team (SDWT), has been used in various ways in several academic libraries. Susan Jurow and Susan B. Barnard have discussed implementing TQM and have offered examples of its effects on libraries. ${ }^{8}$

The SDWT is considered by Kimbrell Fisher to be the most advanced form of empowerment. ${ }^{9}$ Fisher has defined empowerment as having four important variables: authority, resources, information, and accountability. According to 
Fisher, to feel empowered, people need formal authority and all the resources (such as budget, equipment, time, and training) necessary to realize their authority. They also need timely and accurate information to assist in the decision-making process.

\section{The Learning Organization}

The learning organization is an important concept associated with group process and is usually included in the TQM approach in management. Peter $M$. Senge in The Fifth Discipline stated that the learning organization is one where people continually increase their capacity to create the results they truly desire. ${ }^{10}$ In the learning organization, the hierarchical structure is reduced and decision making is decentralized. The learning organization is also a conduit for thinking through the entire system. Failure to conduct a "systems thinking approach" results in shifting problems from one part of the organization to another, never having looked at their root causes.

\section{Method and Approach}

In qualitative research, the case study, one of the ways of reporting such research, is an inductive method. Patterns, themes, and categories emerge from the data, rather than being developed prior to the collection of data. Christine Marlow suggested two main strategies for constructing categories for the analysis of these data: indigenous and researcher constructed. ${ }^{11}$ Indigenous categories use the emic approach, identifying the categories used by those being observed or adopting the native's point of view. On the other hand, researcher-constructed categories, the etic approach, are derived from patterns that are identified within the data. Although the categories may be meaningless to the persons under study, they provide a good overall picture of the phenomena being investigated.

With the decision to attend an academic library conference in May 1996 focusing on the shift in management from hierarchy to teams within the context of
TQM, the author chose to conduct a study of results obtained from the shift and, later, to add more insights into this type of change by comparing the case study to an earlier change at another academic institution. This study explores selected aspects of these changes by addressing the following questions:

- What were the results of the change from hierarchy to teams in an academic library?

- What were the reasons for the change?

- What were the expected outcomes of the change?

- What were the actual outcomes of the change (both internal and external) to the organization?

Based on these research questions, a survey instrument (questionnaire) was developed that included the following questions:

- What were the reasons and intended duration of the change based on organizational objectives? The latter part of the question was used to prompt respondents to think of the change in relationship to goals and objectives already established within the library.

- What were the expected outcomes of the change?

- What were the actual outcomes of the change?

- What were the benefits of the changes, both external and internal? This question was used to see if additional information could be generated on the results of the team approach.

A fifth section entitled "other comments" was added to elicit from respondents other data on their insights concerning the change from hierarchy to the team approach.

Participants were assured that their identities and responses would be kept confidential. This format was used to encourage respondents to answer as freely as possible. The survey instrument was completed by staff volunteers and included all levels of staff (from the previous administrative structure) who made up the teams and one student assistant. 


\section{The Impact of Change from Hierarchy to Teams 575}

The researcher feels that this broad representation of staff provided a wider range of experiences and perceptions.

\section{Case Study Report and Analysis}

University $X$ is located in the southwestern United States. The library began reorganizing in 1993-1994, based on a restructuring blueprint. The plans included hiring a consultant, providing training by the university's Human Resources Department, and introducing some of the concepts of TQM, including emphasizing quality principles and focusing on customers while flattening the organization and providing support for staff. In addition, a new budget process was initiated and the information and reference services departments were restructured. The restructuring of information and reference services served as a refocus for customer service, an objective that was accomplished by conducting needs assessment and customer surveys. Process improvement (PI) projects were started during this phase. First, team leader training was conducted and then intensive team training, which included customer service, project management, valuing diversity, and interpersonal communication. In 1995-1996, expectations of the changes were addressed including team leader and work-related expectations. In addition, emphasis was placed on developing internal and external partnerships. The reasons for the change as perceived by the respondents in this survey are listed in table 1.

The frequency of distribution of the reasons given for change seem to suggest and reflect that, first, training is a very important aspect of change and, second, training had a positive effect on the staff's understanding of the reasons for change. The changes, as reported, may be categorized into short- and long-term changes. Second, the process of change, for the team approach, is evident in the staff's understanding of why the changes were taking place. From this listing, the researcher wanted to ascertain the following: why the change took place as perceived by the staff; how the extent of training was re- flected in the changes; what the relationship was between perceived changes and TQM; and, finally, whether the reasons for change had any relationship to the results attained.

As shown in table 1, the answers of the fifteen respondents (some of whom gave more than one reason for the change) could be categorized into five separate areas:

1. changes in the organization (new dean and changing financial and academic environment);

2. implementation needed (strategic initiatives and new online system);

3. responses to change (access versus ownership report and limited resources / budget);

4. focus on customers (which included responses such as improve customer access to the collection and provide customers with what they want and expect);

5. organizational objectives, which included responses such as create a vision and mission statement, reduce the layers of staffing, collect data to be used in decision making, develop organizational objectives, become a learning organization, build a flexible organization, respond to changing needs in the future, and identify goals and objectives using input from teams.

The staff's observations suggest that the reasons for the change varied, but that all of them are included within organizational goals and that at the heart of the change is an emphasis on customer service. They also suggest that the changes do address issues associated with TQM as well as related issues such as the learning organization, flattening the hierarchy by using the team approach, and using the learning organization concept.

\section{Expected Results versus Actual Results}

The results of the survey were analyzed further by grouping the responses based on three TQM elements: empowerment, customer service, and the learning organization. A line-by-line analysis of the data 


\begin{tabular}{|c|c|c|}
\hline \multicolumn{3}{|c|}{$\begin{array}{l}\text { TABLE } 1 \\
\text { Reasons for the Change: University } X \\
\end{array}$} \\
\hline Reasons for Change & Frequency & $\begin{array}{l}\text { Length of time } \\
\text { delegated to change }\end{array}$ \\
\hline To maximize services and operations & 1 & \\
\hline $\begin{array}{l}\text { To meet the changing needs of the user } \\
\text { community (students \& faculty) }\end{array}$ & 1 & Permanent \\
\hline To improve customer access to the collection & 1 & \\
\hline $\begin{array}{l}\text { To keep the libraries' role as information } \\
\text { provider to customers as an essential role in } \\
\text { a changing information market }\end{array}$ & 1 & \\
\hline To become a learning organization & 1 & Continuous \\
\hline $\begin{array}{l}\text { To form the most effective/efficient teams } \\
\text { (team-based management) }\end{array}$ & 2 & Ongoing \\
\hline New dean & 1 & \\
\hline Implementation of new online systems & 1 & \\
\hline Reduced budget & 2 & \\
\hline Access vs. ownership report & 1 & \\
\hline $\begin{array}{l}\text { Build a flexible organization to respond to } \\
\text { changing needs in the future }\end{array}$ & 1 & Ongoing \\
\hline $\begin{array}{l}\text { Identify goals and objectives (using inputs } \\
\text { from every team) }\end{array}$ & 2 & \\
\hline Create a vision & 2 & 5 yrs. \\
\hline Create a mission & 1 & 5 yrs. \\
\hline Limited resources & 1 & Continuous \\
\hline Reduce the layers of staffing & 1 & 5 yrs. \\
\hline $\begin{array}{l}\text { Focus on the user as the center of the } \\
\text { organization }\end{array}$ & 1 & 5 yrs. \\
\hline Implementation of strategic initiatives & 1 & \\
\hline $\begin{array}{l}\text { Collect data and use the data to make } \\
\text { decisions }\end{array}$ & 1 & \\
\hline Focus on customer needs & 1 & \\
\hline Changing financial, academic environment & 1 & \\
\hline Develop organizational objectives & 1 & \\
\hline $\begin{array}{l}\text { Provide a better organization to meet our } \\
\text { customer's needs }\end{array}$ & 1 & Ongoing \\
\hline $\begin{array}{l}\text { Provide the customers with what they want } \\
\text { and expect }\end{array}$ & 2 & \\
\hline Total & 29 & \\
\hline
\end{tabular}

in this category revealed that the major result the respondents $(75 \%)$ expected to receive from the change from hierarchy to teams was improvement in customer service. The results are explained in more detail in the following subsections.

\section{Customer Service}

The data reveal that some level of customer service already exists and that the staff strongly desire to increase their level of customer service. One of the ways staff wanted to improve customer service was to respond more quickly to customer needs. In addition, there is interest in using a systems approach (regarding the organization as a total system, interdependent and interrelated) to focus on customer service, and in order to accomplish these tasks, there is a need for train- 


\section{The Impact of Change from Hierarchy to Teams 577}

ing. These concerns were voiced in many ways, from the general statement "improving customer service," and "positioning the library to become more customer focused" to more specific changes that had to do with the structure of the library. These responses included "become more 'customer oriented' as opposed to collection oriented" and "make the services that we provide in the library more oriented toward customer needs, less oriented toward internal convenience/traditions." There also were expected results that related directly to how staff might accomplish the results they intended, such as "help develop skills to respond to customer needs" and "share in decision making, respond to change, become involved in strategic planning, and save time and money."

\section{Empowerment}

Another result the respondents wished to achieve was empowerment. All other "wishes" included equal status; for example, "address future needs, work on strategic planning, accept new challenges, include more persons in the decisionmaking process, develop new skills," and the specific result of "shelving books more efficiently."

It is clear from the survey that by empowerment, staff meant that they would like to become more involved in the decision-making process. They either had not been pleased with some of their decisions or were not pleased with the process by which they arrived at decisions because they reported wanting to make better decisions. The means by which they wanted to gain decision-making power was to flatten the organization and have full participation, again an implication that systemwide participation was needed.

\section{The Learning Organization}

Based on the problem-solving nature of the learning organization, the respondents reflected the need for a team-based work environment that would produce better decisions and use this approach as a means to improve processes (for in- stance, shelving books for the same or less money). Moreover, the data indicate that staff members intend to continue this process into the future, as well as to plan their future.

\section{Perceived Actual Results}

Was the major result expected by the respondents realized; that is, was customer service improved? Fifty percent of the responses referred to an improvement in customer services and also gave some indication of the processes by which customer satisfaction might be gained, as reported by one of the respondents:

Use of the in-depth data studies by cross-functional teams have resulted in more efficient ways of providing services to our customers.

Others gave evidence that substantiated these results, including one respondent who stated that by "responding and cooperating better with our customers, [we are] questioning long-held obsolete beliefs and practices." Furthermore, there were indications that the staff perceived the changes as an ongoing process: "We are more customer focused and continually assessing our customer needs."

One aspect of customer results may well exceed the above-mentioned experience. The book-shelving team achieved excellent results. They saved thousands of dollars and were able to improve greatly their rate of reshelving books. Their tremendous success was achieved by examining the process by which books are reshelved, which revealed several redundant steps.

A significant portion of the data regarding the actual results that were attained centered on the "change process." This is one of the significant findings of this study-that change itself, or the management of change, is a central concern in the change from hierarchy to teams. What was significant about these changes? The survey reflects that change was sometimes difficult and in some cases remained difficult. Yet, the change 
was a worthwhile process given the positive attributes to the improvement in customer services. Some of the difficulties of change as reported by one respondent indicated that some staff were not "change ready," an observation confirmed by another respondent:

At first, staff did not want to hear about planning for the change, they thought it was a gimmick. The second year, they began to see that change was happening. The change was here! They began to take notice. In the third year, they began to 'come around,' they saw the 'tiein.' Projects are continually being supported. We are prioritizing and people are 'airing their feelings.'

The first part of the above statement reflects the difficulty of the change, the middle part emphasizes the payback that resulted from the staff's apparent patience, and the last part represents some level of comfort that staff members are gaining by remaining involved in the change process.

\section{Levels of Change}

One way to judge the effects of change is to assess the results based on the various levels where changes were made. The two major levels of change in this study are internal and external; however, there is another level where the external and internal levels overlap. The external level may be viewed by the two constituencies represented, faculty and students; publishers and vendors form a second external group.

On the level of internal benefits, the theme of customer satisfaction remains a major focus in the data. The staff are more aware of customer needs and thus better able to meet them. Such needs, they report, were gained from focus groups and needs assessment research. The staff also were empowered to make decisions at the front desks, which meant fewer problems for the customers. Customers no longer had to go from one area to another to have their problems solved. The apparent feeling of increased customer satisfaction was confirmed by another respondent who stated: "Customers do not wait for a guru; on the whole, every employee is working to be that guru."

The theme of empowerment also is evident in these data. One respondent noted that the teams realized that they used interrelated processes that sparked more sensitive and meaningful communication:

- The staff became more involved and had more varied duties; there was more "voice" for the staff.

- The staff became more proactive and creative.

- The staff formed more partnerships within the library.

- The team approach was used as an opportunity to make an intentional focus on diversity.

The team approach also provided an opportunity for staff to operate in different settings. The technical services staff worked in public services, and career staff were permitted to participate in management-level areas. As reported by one respondent, the negative effect of layoffs (as had been feared) did not occur in this change from hierarchy to teams.

From a typically more traditional point of view of the budget, the results of the change from hierarchy to teams reflected that in the team approach (decentralization), there was a better understanding of the budget process and the allocation of resources. Moreover, it was easier to match resources with strategic needs. A case in point was the allocation of more resources to the reshelving of books to improve that process, although in the end, after an examination of processes, there was a savings in money and greatly improved service. Again, a better understanding of customer needs echoes earlier findings in the external benefits of the data. Staff were not only able to respond to customer needs, but to respond more quickly. Customers received better service as a result of improved processes. 
The Impact of Change from Hierarchy to Teams 579

Areas where the internal and external benefits overlap include: the formation of partnerships within the library and with faculty and departments; a better understanding of the budget processes that will directly benefit the customers; the development of staff skills that could be applied at workplaces outside the library; and the adoption of a proactive approach with both customers and publishers. In turn, the staff saw more clearly how the publishing market affects the work of libraries.

\section{Other Comments}

As stated earlier, this section of the survey solicited information the respondents felt was worth adding to the questions they were asked: What were the reasons for the change? What were the intended results of the change? What were the actual results of the change (internal and external)? Six of the twentyfour respondents chose to answer questions in this section.

The elements of change the respondents focused on included: the change process itself and its difficulties and triumphs; the effect of the change on the budget process and the staff; and the framework the change in structure provided for addressing the future. One respondent reported this as follows:

Getting to a team-based organization is a long, protracted and difficult process, but it will provide [the mechanism] for building an organization that can survive and thrive in the changing world of libraries.

The first part of the statement ("getting to a team-based organization") reflects a part of the difficulty; it is not easy to change from one approach to another. Another respondent confirmed this insight:

Change on an organizational level is hard, on a personal level, even more so. But the positives of being able to provide better service to our customers is energizing and outweighs the difficulties.

The affirmative side of the change is observed in the latter part of the respondent's remark, which is a confirmation of the major focus throughout these data-that improving customer service remains the major reason for the change.

Another part of the problem (in addition to organizational and personal difficulties) involves the respondent who commented:

Overall, with the team-based management we are to provide more service with less staff. With the focus on user self-sufficiency, we were able to automate and upgrade our systems, thus allowing the library to move into the future and be more viable for university funding.

One of the strongest points that demonstrated how the change from hierarchy to teams positively affected the budget process is reflected in the latter half of this statement. One respondent explained that focusing more on customer service meant providing more service, a shift that could better substantiate the viability of the library to the university. The library in this instance was assisted by the fact that the university administration had both encouraged and supported the change and also had supported the library with training and guidance from the university's Human Resources Department.

The institution also benefits when the work experience provides students with a connection to the university and has a positive effect on student retention rates.

Despite the difficulties experienced by the staff, the "other comments" section also revealed their commitment to continue to refine the new process, including items such as the amount of paper 


\section{College \& Research Libraries}

generated and the amount of time spent training and hiring. In addition, the new structure provided a framework that would take the staff into the future, address continual change, and assist staff in meeting the ever-changing needs of the customers, all of which emphasize the learning organization.

\section{Major Findings}

The major focus of this case study, as revealed by the respondents, shows a very clearly concentrated effort by the staff to improve customer service. The research, however, suggests the need for a broader basis of understanding of customer service. Customer service as defined in this case study focuses on external customers to the library. A broader base for defining the "customer" would be to include the staff as a part of the "customer" category (internal customer).

A second important finding of this research is its implications for the use of student assistants in academic libraries. According to David Gregory, ARL statistics reflect that student assistants make up 24 to 28 percent of academic library staff. ${ }^{1}$ Student assistants contribute to institutions in several ways, including making the libraries less intimidating to their peers-sometimes students find asking their peers questions easier than asking librarians. There are also indications in the literature of a few of the shortcomings of these decisions. The institution also benefits when the work experience provides students with a connection to the university and has a positive effect on student retention rates. Moreover, seeking to fulfill the university's commitment to diversity may be achieved through the selective hiring of student assistants to help the university achieve a more culturally diverse workforce-one that, according to Jane McGurn Kathman and Michael D. Kathman, should be a proactive approach where the student employee group mirrors the composition of the larger student body. ${ }^{2}$ Finally, according to Maurice B. Wheeler and Jacqueline Hansen, student assistants are a source

\section{November 1999}

of recruitment to the profession of librarianship. ${ }^{3}$ They point out that a significant amount of research suggests that personal contact with librarians is a major determinant in many people's decisions to pursue careers in the profession. The team approach also indicates how students can both contribute and receive greater benefits in the workplace, as reported by the one student worker in the study:

As a student in the library, this [the team approach] has given me the opportunity to learn more working with a team with varying job responsibilities than I may have otherwise had.

It is clear from the data that in some instances, the actual results sought in this change from hierarchy to teams exceeded the intended results. The first result is the importance of taking into consideration the challenges that come with instituting change in an organization. It seems clear that, even though training was available to staff on the issue of change, change still must be addressed on an ongoing basis.

The emphasis on partnerships is a new insight. More often than not, the importance of partnerships in the traditional literature is focused on librarians with their constituencies outside the library, not among themselves. This study emphasizes the importance of librarians establishing partnerships within the staff of the library. Such partnerships help to establish better levels of communication patterns, goal-setting plans, problemsolving perspectives, and strategies for improving customer services.

Despite the benefits of the team approach, however, it is important to look at the shortcomings that might result for those staff members who seek some level of individual satisfaction in addition to the satisfaction they gain from the team approach.

Although the major emphasis of empowerment in TQM centers on the li- 
The Impact of Change from Hierarchy to Teams 581

brary staff, this study suggests that the library's customers also have benefited from empowerment. Empowerment for the external customer is in the form of gaining self-sufficiency in using library resources.

\section{Comparison of Data: University $\mathbf{X}$ and Duke University}

A comparison (mostly of similarities) of the two schools, University $X$ and Duke University, is based on the survey and on library documents examined that pertained to the change from hierarchy to teams. In addition to comparing the data based on the three major components of TQM (the learning organization, customer service, and empowerment), this analysis includes researcher-constructed themes as defined earlier by Marlow. ${ }^{4}$ Such themes are designated as the etic approach in qualitative research; they are derived from patterns identified in the data. Although the themes may be meaningless to the persons under study, they provide a good overall picture of the phenomena being investigated. These themes are mission, diversity, and trust. An additional focus included a discussion of the question, What was the nature of the shift from hierarchy to teams in the two settings?

The periods during which the two schools began the discussion of a change from hierarchy to teams are different: Duke began in 1984-1985, and University X began in 1993-1994. However, the reasons for making the change were very similar: technology, improved user or customer services, the desire to become involved or more involved in decision making, budget considerations, and, in the case of Duke, an improved ranking in ARL. In addition, University $X$ had just hired a new dean of the library school. Prior to the change in management, Duke's staff was using a participative management approach; it is unclear from the data which approach University $X$ was using before the change was made from hierarchy to teams. It is clear that both schools had the support and encour- agement of university management and used the expertise and training of their respective Offices of Human Resources, and in the case of University $X$, additional external consultants.

\section{Learning Organization, Empowerment, and Customer Service}

Both schools used the team approach to examine problems in the library consistent with the learning organization. As a result of examining processes and identifying a large level of redundancies (handling books many more times than needed to get them back on the shelf), Duke created a new unit for retrospective conversion from their savings. By using this same approach, University $X$ was able to save thousands of dollars and get the books back on the shelves in a much shorter period of time.

The level of empowerment is similar. Both universities identified empowerment for staff as being involved in an increased level of decision making. For students at University $X$, empowerment meant gaining self-sufficiency. Duke introduced a third level of empowerment: After the power to make decisions was placed closer to the persons actually involved in the work, the team leader had more time to assist the director of libraries in matters of development and library vision. Both schools also took a systems approach toward addressing the decision-making process.

Customer service, the third component of TQM, is closely related to empowerment. Both schools already had a focus on customer service and wanted to improve on what they had. Throughout the data, the respondents of University $X$ made clear their consistent focus on customer service as the major reason for the change. The examination of processes to attain better customer service was the same for both schools.

Under the rubric of the TQM approach, Lubans listed four factors used to empower: coaching, consulting, encouraging, and leading. ${ }^{5}$ Under the heading of 


\section{College \& Research Libraries}

consulting, he described the approach at Duke: through negotiating with external and internal customers, empowerment was achieved. Moreover, the Duke Internal Customer Feedback tool was appropriated to accomplish this goal. Evidence of all three TQM components is observed in these data. The following subsections discuss three additional themes that emerged in the data: trust, diversity, and mission.

\section{Trust}

The concept of trust arose in the data of both schools and from different points of view. On the part of University X, trust emerged as it related to the relationships that developed among staff as a result of the change from hierarchy to teams. In response to the question, What were the actual outcomes of the change from hierarchy to teams? one respondent stated: "A lot of trust between employees and an improved desire to do a great job." Another respondent answered similarly to the question, What were the benefits of the change? The staff member stated: "People are more comfortable [with] and trustworthy [toward] each other."

Trust was identified in the data from Duke University in Lubans's discussion on the barriers encountered in the change from hierarchy to teams. He described this contingency:

The potential problem lies in the fact that in the absence of an annual written evaluation, an employee may experience insecurity. This is not so much out of a desire for recognition, which might be nice, but often because of a lack of trust. A "good" evaluation is like money in the bank if one believes management is prone to capriciousness. ${ }^{6}$

Building trust is a very encouraging outcome of the change from hierarchy to teams as seen in the data from University $X$. On the other hand, the caveat sounded by Lubans regarding the possibility of insecurity in his assumptions of

\section{November 1999}

the barriers to the success of TQM is a point to be taken seriously. The possibility of creating an environment where job security is an ongoing concern is a realistic response given normal staff concern for good, individual written appraisal in the event of a job change. However, it should be noted that at Duke a part of the encouraging process (one of the ways of empowering) includes recognizing and giving attention to high performance.

\section{Mission}

In Library and Information Center Management, Robert D. Stueart and Barbara B. Moran enumerate examples of college and university mission statements. ${ }^{7}$ Among these examples, Harvard University notes in its mission statement that five principles should govern the library of the future: unity of vision, stewardship, quality, collective action, and cooperation. Both schools in this study have sought to make changes that will better serve their respective institutions. Lubans stated that the library staff had been experimenting since 1985 with new organizational structures to achieve a superior stewardship of the resources assigned to them by Duke University. ${ }^{8} \mathrm{~A}$ writer for University $X$ made a similar statement that showed regard for planning for both the present and the future to achieve the university's mission.

\section{Diversity}

Several organizations are including diversity as a part of their mission statements. Traditionally, libraries have emphasized diversity through collection development, access to services, and the preservation of the history and literature of various cultures. More recently, however, this emphasis has broadened to include diverse staff and a more intentional effort to become more tolerant of different approaches and ideas to better meet the overarching goals and objectives of library organizations.

Evident in the data are examples of a focus on diversity. In the case of Univer- 
The Impact of Change from Hierarchy to Teams 583

sity $X$, the team approach was used as a means of focusing on diversity. Diversity training was provided by outside consultants. In addition, Diversity Roundtables were offered to library staff on a variety of topics, including the significance of holidays of various cultures. In addition, efforts were made to educate library staff on the Library Affirmative Action Committee and to state the university's and library's commitment to affirmative action and diversity. University $X$ also has its own diversity mission statement as well as a Diversity Council. At Duke, various examples were reported by Lubans that point to an emphasis on diversity, first on a department or system level where staff became more accepting of differences and appreciative of the potential value they represented. On the level of team leadership, different perspectives were sought out because differences no longer were shuttered by the dominant culture.

\section{Hierarchy}

What was the nature of the change from hierarchy to teams in the two settings? Did the change actually occur? One of the problems with hierarchy is that inherent in its design is the placement of the decisionmaking power at the tip of its symbolthe pyramid. The data substantiate the fact that definite changes were made. In both instances, the power to make decisions was given to those individuals closest to the work. In the case of Duke, where decisionmaking power was granted to teams, there was an instance where some department heads were allowed to choose not to become team leaders, which left a portion of the hierarchy intact. At University $X$, in addition to the decision-making power accorded to teams, the Dean's Council's name was changed to the Library Cabinet to reinforce the idea that this body is responsible to the library and not just to the dean. It is, therefore, evident from the data that both schools experienced some change in the hierarchy. But to what degree has that change occurred? Is there an inherent need for some degree of hierarchy? In the final analysis, the degree to which change in the hierarchy actually occurred is probably best explained by Lubans:

We pushed the hierarchy to its productivity limits, virtually taking a team-based approach within the hierarchy. ${ }^{9}$

\section{Conclusions}

The purpose of this article was to analyze the impact of the change (or perceived change) in management approach from hierarchy to teams and to look at the differences between the expected and actual results that the change engendered. These results have been demonstrated in the data; however, there is a need to repeat that the actual results, despite the challenges of the process of change, exceeded the intended results. For example, Duke reported having the process itself validated. This was not an intended result of moving from hierarchy to teams. The survey also indicated that the major components of TQM (empowerment, the learning organization, and the team approach) were accomplished in these settings.

This study also points out the challenge that faces managers in helping staff switch from one approach to another. It is important to better understand the dynamics of change and how it can best be managed. There is the additional responsibility of managing ongoing change.

Finally, not-for-profit institutions are continuing to take cues from the for-profit sector in management by using strategies such as marketing, benchmarking, and TQM. The time also may have come for librarians/information professionals to reexamine their posture toward the forprofit and not-for-profit separation. Such a change would be consistent with what has happened in at least one other discipline regarding a similar challenge. Sociologist Peter M. Blau developed his Social Exchange Theory along economic lines. ${ }^{10}$ Rather than view economic in a material manner to mean "exact payment for specified goods" as economists do, the term is defined as a "nonmaterial" entity. A smile or a kind gesture is an example 
of a nonmaterial economic entity, particularly as it relates to human interaction. One respondent in this study may have confirmed this viewpoint:

Within our organization, the change was good; however, I think the critical factors are overlooked because we are termed as a nonprofit organization, and with this [I feel] we lose vision from time to time. I think we need to push that we are for-profit and realize that profit as satisfied customers.

\section{Notes}

1. David Gregory, "The Evolving Role of Student Employees in Academic Libraries," in Libraries and Student Assistants: Critical Links, ed. William K. Black (New York: Haworth Pr., 1995).

2. Jane McGurn Kathman and Michael D. Kathman, "What Difference Does Diversity Make in Managing Student Employees?" College and Research Libraries 59 (Sept. 1998): 378-389.

3. Maurice B. Wheeler and Jacqueline Hanson, "Improving Diversity: Recruiting Students to the Library Profession," in Libraries and Student Assistants: Critical Links, ed. William K. Black (New York: Haworth Pr., 1995).

4. Marlow, Research Models for Generalist Social Work, 235.

5. Lubans, "I Ain't No Cowboy, I Just Found This Hat," 34-35.

6. Ibid., 32.

7. Robert D. Stueart and Barbara B. Moran, Library and Information Center Management (Englewood, Colo.: Libraries Unlimited, 1993).

8. Lubans, "I Ain't No Cowboy, I Just Found This Hat," 29.

9. Ibid.

10. Peter M. Blau, Exchange and Power in Social Life (New York: Wiley, 1964). 